\title{
A study of the health profile of rubber plantation workers in rural Kerala
}

\author{
Tapas Sadasivan Nair ${ }^{1}$, Suneela Garg ${ }^{2}$, Mongjam Meghachandra Singh ${ }^{3}$ \\ ${ }^{1}$ Resident, ${ }^{2}$ Director-Professor, ${ }^{3}$ Professor, Department of Community Medicine, Maulana Azad Medical College, New Delhi, India
}

Background: The state of Kerala produces nearly $90 \%$ of India's natural rubber output. Rubber plantation workers are vulnerable to a variety of health hazards and being in the unorganized sector, do not enjoy the benefits that their counterparts in organized sector enjoy. Hence, monitoring of their health needs to be done periodically. Aims and Objectives: 1. To assess the health status and common illnesses of rubber plantation workers. 2. To detect the prevalence of non-communicable diseases like diabetes and hypertension among rubber plantation workers. Materials and Methods: A cross-sectional study was conducted amongst 154 rubber plantation workers in Pathanamthitta District in the state of Kerala, India in September 2014. Data was collected using a predesigned pretested and semistructured questionnaire containing items to assess the socio-demographic profile, their medical history and individual hazard exposure. Data was analysed in SPSS Version 16. Results: Chemical exposure was the most common hazard reported by rubber plantation workers $(70.1 \%)$. The most common health complaints were musculoskeletal $(66.2 \%)$, respiratory $(31.2 \%)$, dermatological $(26.6 \%)$ and ophthalmological disorders (22.7\%). 20.1\% prevalence of diabetes and $29.9 \%$ prevalence of hypertension was detected among study subjects; awareness and treatment seeking behaviour was poor. Conclusions: Proper health and safety training of rubber plantation workers on workplace hazards and ergonomics is essential to reduce work-related morbidities. Efforts should be made to enhance their access to healthcare and provide periodic health checkups.

Key words: Occupational health, Rubber plantation workers, Health hazards, Health profile
http://nepjol.info/index.php/AJMS DOI: 10.3126/ajms.v7i3.13288 E-ISSN: 2091-0576 P-ISSN: 2467-9100

\section{INTRODUCTION}

India is the fourth largest producer of natural rubber in the world. The cultivation of rubber trees (Hevea brasiliensis) as a cash crop in India was initiated by the British in the $19^{\text {th }}$ century mainly in Assam and Kerala. As the tropical climatic conditions and hilly undulating terrain of Kerala was extremely favourable for the growth of rubber trees, rubber plantations flourished and Kerala eventually became the dominant producer of natural rubber in the country, producing as much as $90 \%$ of India's rubber output. ${ }^{1}$ Majority of the producing units are small growers (with plantations less than 20 hectares) and hence the tapping of rubber trees for latex is mainly a manpower intensive enterprise, depending on skilled yet seasonal labourers to perform the 'tapping' of the trunks of rubber trees to get the optimum output of latex as well as to later process the latex with formic acid in order to create rubber sheets.

Plantation workers all over the world are exposed to hazardous working conditions, such as exposure to pesticides, working long hours in hot humid climates, and working with dangerous machinery. These working conditions predispose them to a variety of health problems like respiratory, dermatological and musculoskeletal disorders. ${ }^{2-4}$ The health risks associated are also determined by the length of time exposed, type of work engaged in, the work environment and the personal protective measures employed. In addition to this, they often suffer from various morbidities related to their environment like snake bites, ${ }^{5}$ nematode infections ${ }^{6}$ and vector borne diseases like 
malaria, ${ }^{7}$ dengue ${ }^{8}$ and chikungunya. ${ }^{9}$ Non-communicable diseases is also an emerging concern of late. ${ }^{10}$ Aside from the direct impact on workers' health, work-related ailments and illnesses may affect their productivity, job tenure and satisfaction.

Rubber plantation workers are a part of the informal occupational sector in India. Hence, they do not have any organized occupational health services. Further, very limited attempts have been made to study the occupational exposure and health profile of this population in India. Therefore, the present study was undertaken to assess their health status and common illnesses, as well as to detect the prevalence of non-communicable diseases like diabetes and hypertension among them.

\section{MATERIALS AND METHODS}

\section{Study settings and participants}

It was a community based cross-sectional study conducted among rubber plantation workers working in Kozhencherry Taluk $\left(9.3388^{\circ} \mathrm{N} 76.7127^{\circ} \mathrm{E}\right)$ in Pathanamthitta District of the state of Kerala, India. Pathanamthitta District was chosen as it is the second most productive district in Kerala for natural rubber output and the taluk was selected randomly. Kozhencherry Taluk covers an area of 8 square kilometres and has a population of 14,000 as per the Census of India 2011. ${ }^{11}$ There are numerous rubber plantations in the area, and the workers are located in or around these plantations. Taking prevalence of morbidities among rubber plantation workers to be $50 \%$ (as there are no comprehensive studies in the Indian setting) with $95 \%$ confidence interval and precision of $10 \%$, the sample size was estimated to be 96 . However, 154 rubber plantation workers working in the area consented to participate.

\section{Inclusion criteria}

All workers involved in rubber plantations for at least 1 year were included in the study.

\section{Study period}

The study was conducted over a period of two weeks in September 2014.

\section{Study tool}

A pre-tested, semi-structured interviewer based questionnaire was used for data collection. The questionnaire was prepared after a rigorous literature review..$^{2-10}$ The questions were then assessed for suitability, relevance and accuracy in the Indian context. The interview schedule was pretested on 25 rubber plantation workers from Thekkemala village in Pathanamthitta District of Kerala. As a result of this pretesting, some of the items on the questionnaire were discarded mostly due to ambiguity of these questions while others were revised to ensure that the participants would comprehend the meaning of the question.

The schedule included questions pertaining to age, gender, state of origin, marital status, education, income and type of housing of the study participants. The schedule also included items for assessment of exposure to chemicals, heat, fumes and noise on daily basis. Past history of diseases such as skin diseases such as contact dermatitis, allergies, fungal infections, musculoskeletal disorders such as low back pain, knee joint problems, pain in feet, respiratory symptoms such as breathlessness, cough, wheeze, etc., eye related symptoms like irritation, watery eyes, etc, worm infestations, vector borne diseases like malaria, dengue and chikungunya in the last one year were elicited from the participants.

\section{Study methodology}

Before the commencement of the study, a thorough survey of all rubber plantations was undertaken. After mapping these places, the rubber plantation workers were located and contacted. A three-member team led by the investigator interviewed the workers present on the day of survey. The objective of the study was explained to them and informed consent was obtained before the collection of data. The subjects were then interviewed regarding their sociodemographic status and health profile. In addition to this, their blood pressure and fasting blood sugar was measured as per JNC 8 and WHO guidelines respectively. ${ }^{12,13}$

The option to opt out of the study was kept open without any clause. Confidentiality of data was ensured. The Ethics Committee of the institution approved the protocol of the study.

\section{Statistical analysis}

The collected data was entered into Microsoft Excel and then analyzed using Statistical Package for the Social Sciences Version 16. Descriptive statistics, including mean and standard deviation for quantitative data and proportions for qualitative data were used to characterize the study population.

\section{RESULTS}

\section{Socio-demographic profile of workers}

Overall 154 male rubber plantation workers consented to participate. The mean age of study group was $34.3 \pm 4.8$ years with a range of 21-65 years. Majority of the respondents were married $(\mathrm{n}=136 ; 88.3 \%)$. Nearly onethird of the participants $(n=48 ; 31.2 \%)$ were educated up to primary level, whereas $40.9 \%(\mathrm{n}=63)$ were illiterate. 103 subjects $(66.9 \%)$ were residing in rented accommodations 
near the plantations while $14.3 \%(n=22)$ were staying in quarters and $18.8 \%(n=29)$ in slum clusters. Only 59 workers $(38.3 \%)$ belonged to Kerala; the rest were from other states like Tamil Nadu (22.1\%), Andhra Pradesh $(17.5 \%)$, Orissa (13.6\%) and Bihar (8.4\%). Mean income during the rubber tapping season was Rs 400 per day. A majority of workers had more than 3 years of working experience in rubber plantations $(81.2 \%)$ (Table 1$)$.

\section{Exposure to occupational hazards}

Chemical exposure $(\mathrm{n}=109 ; 70.1 \%$ ) was reported to be the most common hazard at the rubber plantation by the

\begin{tabular}{|c|c|}
\hline Socio-demographic variables & Total $[n=154]$ \\
\hline Age in years (mean $\pm S D)$ & $34.3 \pm 4.8$ \\
\hline \multicolumn{2}{|l|}{ Gender (\%) } \\
\hline Male & $154(100)$ \\
\hline \multicolumn{2}{|l|}{ Marital status (\%) } \\
\hline Married & $136(88.3)$ \\
\hline Unmarried & $18(11.7)$ \\
\hline \multicolumn{2}{|l|}{ Educational status (\%) } \\
\hline Illiterate & $63(40.9)$ \\
\hline Primary school & $48(31.2)$ \\
\hline Secondary school & $34(22.1)$ \\
\hline High secondary school & $9(5.8)$ \\
\hline Graduate & 0 \\
\hline Post graduate & 0 \\
\hline \multicolumn{2}{|l|}{ Type of housing (\%) } \\
\hline Slum clusters & $29(18.8)$ \\
\hline Rented accommodation & $103(66.9)$ \\
\hline Employer/company quarters & $22(14.3)$ \\
\hline Income (mean) & Rs 400 per day \\
\hline \multicolumn{2}{|l|}{ State of origin (\%) } \\
\hline Kerala & $59(38.3)$ \\
\hline Tamil Nadu & $34(22.1)$ \\
\hline Andhra Pradesh & $27(17.5)$ \\
\hline Orissa & $21(13.6)$ \\
\hline Bihar & $13(8.4)$ \\
\hline \multicolumn{2}{|l|}{ Years of work (\%) } \\
\hline $1-3$ & $29(18.8)$ \\
\hline $4-6$ & $35(22.7)$ \\
\hline $7-9$ & $63(40.9)$ \\
\hline$>9$ & $47(17.5)$ \\
\hline
\end{tabular}

\begin{tabular}{lc}
\multicolumn{2}{l}{ Table 2: Self-reported health problems of rubber } \\
plantation workers in last one year \\
\hline \multicolumn{2}{l}{ Diseases/problems } \\
\hline Musculoskeletal problems \\
- Neck pain & $102(66.2)$ \\
- Lower back ache & $85(55.2)$ \\
- Knee pain & $78(50.6)$ \\
Respiratory problems & $54(35)$ \\
Dermatological problems & $48(31.2)$ \\
Ophthalmological problems & $41(26.6)$ \\
Vector borne diseases & $35(22.7)$ \\
Worm infestations & $17(11)$ \\
Snake bites & $5(3.2)$ \\
\hline Note: Responses are not mutually exclusive & 0 \\
\hline
\end{tabular}

workers, followed by fumes ( $\mathrm{n}=51 ; 33.1 \%$ ), dust/smoke $(\mathrm{n}=29 ; 18.8 \%)$ and heat $(\mathrm{n}=23 ; 14.9 \%)$. Noise was reported the least ( $\mathrm{n}=15 ; 9.7 \%$ ) (Figure 1$)$.

\section{Self-reported health problems among welders}

Musculoskeletal disorders were the most commonly reported health problems by the workers such as neck pain, lower back ache and knee joint problems $(n=102 ; 66.2 \%)$ followed by respiratory problems $(\mathrm{n}=48 ; 31.2 \%)$, dermatological problems $(\mathrm{n}=41 ; 26.6 \%)$ and ophthalmological problems $(n=35 ; 22.7 \%)$ in the last year. A few cases of vector borne diseases and worm infestations were also reported (Table 2).

Prevalence, awareness and treatment seeking behaviour of diabetes and hypertension

Out of the 154 study participants, the prevalence of diabetes was found to be $20.1 \%(n=31)$ while hypertension was found to be 29.9\% ( $\mathrm{n}=46)$ (Figure 2).

It was noticed that a majority of rubber plantation workers who were found to have diabetes were unaware of their diabetic status $(n=20 ; 64.5 \%)$. Thus, only 11 subjects $(35.5 \%)$ were aware of their diabetic status, out of whom $6(19.4 \%)$ were on treatment (Figure 3a). Similarly, most of the subjects who were detected to have hypertension were not aware of their hypertensive status ( $n=36 ; 78.3 \%$ ). Hence, only 10 participants $(21.7 \%)$ were aware of their hypertensive status, out of whom $4(8.7 \%)$ were on treatment (Figure 3b).

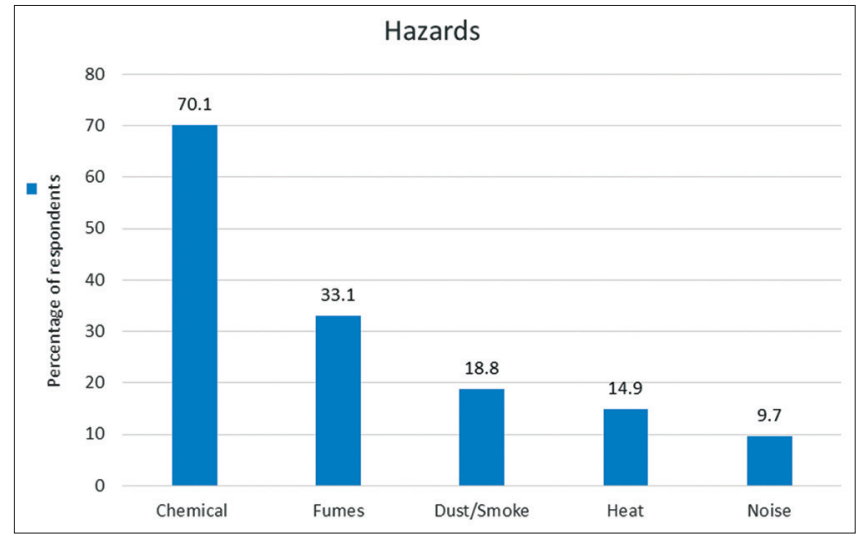

Figure 1: Self-reported Exposure to Various Hazards at Rubber Plantations

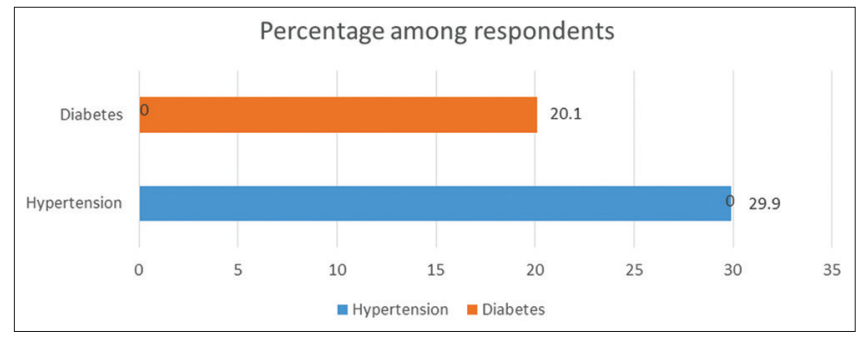

Figure 2: Prevalence of diabetes and hypertension among rubber plantation workers 


\section{DISCUSSION}

Working in rubber plantations is an important activity in the informal sector with significant contribution to the GDP of Kerala as well as India and, as with other occupations, it is not without health risks. However, this population has been studied only to a limited extent in Indian settings. Hence, the present study attempted to assess the health hazards faced by rubber plantation workers as well as their various morbidities at the time of survey and a year prior to it.

The workers in this study were all males pointing towards the gender predisposition towards this occupation, especially in a developing country like India. Besides, males tend to select themselves into more hazardous and physically demanding jobs while females are assigned less physically demanding jobs. The finding that participants were in the 21-65 years age group is consistent with findings by Reddy et $\mathrm{al}^{4}$ where the age distribution of tappers was found to be 28-62 years. Another notable characteristic of the study population was that it predominantly comprised of migrants from other states. This could be attributed to the shortage of manpower in Kerala due to the prevailing trend of external migration to countries in the Middle East. ${ }^{14}$ An overwhelming majority of the workers $(94.2 \%)$ were educated upto secondary level $\left(10^{\text {th }}\right.$ standard $)$ or less, yet they engage in work that requires considerable skill. This is comparable to Reddy et al's corresponding finding of $87.3 \%$ of subjects who have not studied beyond secondary level. ${ }^{4}$

Chemical exposure was reported to be the major health hazard of rubber plantation workers in the present study. This is in agreement with existing literature on the effects of prolonged pesticide exposure as well as latex sensitivity among rubber plantation workers done in various countries. ${ }^{2,3}$

The predominant morbidities reported by the study subjects over the past year were musculoskeletal, respiratory and dermatological ailments. The major musculoskeletal problems that were noted in the current study - neck pain, lower back ache and knee pain - are comparable to the study by Reddy et al, which reported neck pain $(72.2 \%)$, low back pain (66.2\%), shoulder pain (44.9\%), knee pain (55.8\%), ankle/ feet pain $(34.4 \%)$, elbow pain $(33.2 \%)$, upper back pain $(30.8 \%)$, wrist pain $(50.1 \%)$ and hip/thigh pain $(15.3 \%)$ as the most common musculoskeletal disorders among rubber tappers. ${ }^{4}$ Respiratory and dermatological manifestations have been studied by Chester at al in Malaysian rubber plantations, but the role of the pesticide paraquat was ruled out. ${ }^{2}$ Kumar et al noted a borderline significant difference in the alteration of lung function in rubber tappers with respect to controls in their study in Kerala. ${ }^{4}$ Further research is necessary to evaluate and quantify possible associations of pesticides, latex and the acid used to process latex with respiratory, dermatological, and ophthalmological manifestations in rubber plantation workers. Vector borne diseases and worm infestations were also been reported, albeit in fewer numbers than expected when compared with other studies. ${ }^{6-9}$ This could be due to better awareness of these diseases among workers and usage of personal protective measures like insecticide treated bednets, mosquito repellants and footwear.

The present study reported $20.1 \%$ prevalence of diabetes among the study subjects and $29.9 \%$ prevalence of hypertension. This is comparable to a community based study in Kerala by Thankappan et al comprising 7449 subjects, which reported $14.3 \%$ prevalence of diabetes and $33.9 \%$ prevalence of hypertension among men. ${ }^{15} \mathrm{It}$ was also noted in the current study that only $35.5 \%$ of all diabetics were aware of their diabetic status and $19.4 \%$ were treated, while only $21.7 \%$ of all hypertensives were aware of their hypertensive status and $8.7 \%$ were treated. This was considerably lower than the findings of Thankappan et al, who reported that $71.1 \%$ of all diabetics were aware and $64.9 \%$ were treated while $29.8 \%$ of all hypertensives were aware and $21 \%$ were treated. ${ }^{15}$ The lower findings in current

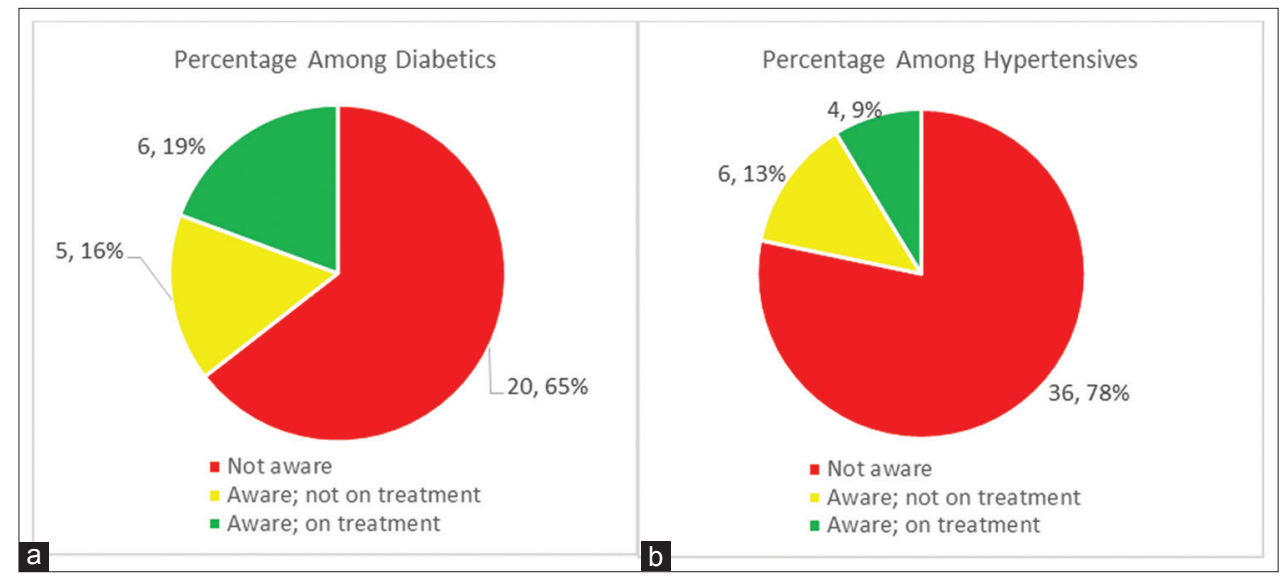

Figures: $(a, b)$ Awareness and treatment seeking behaviour of diabetic and hypertensive rubber plantation workers respectively 


\begin{tabular}{|c|c|c|c|c|c|c|c|}
\hline \multicolumn{4}{|c|}{ Diabetic subjects (\%) } & \multicolumn{4}{|c|}{ Hypertensive subjects (\%) } \\
\hline \multicolumn{2}{|r|}{ Aware } & \multicolumn{2}{|r|}{ Treated } & \multicolumn{2}{|r|}{ Aware } & \multicolumn{2}{|r|}{ Treated } \\
\hline $\begin{array}{l}\text { Present } \\
\text { study }\end{array}$ & Thankappan et al & $\begin{array}{l}\text { Present } \\
\text { study }\end{array}$ & Thankappan et al & $\begin{array}{l}\text { Present } \\
\text { study }\end{array}$ & Thankappan et al & $\begin{array}{l}\text { Present } \\
\text { study }\end{array}$ & Thankappan et al \\
\hline 35.5 & 71.1 & 19.4 & 64.9 & 21.7 & 29.8 & 8.7 & 21 \\
\hline
\end{tabular}

study underscores the lack of awareness and poor treatment seeking behaviour among this segment of the population and emphasizes the importance of public health education and physician education as complementary strategies to combat the increasing burden of non-communicable diseases and their risk factors (Table 3).

\section{CONCLUSION AND RECOMMENDATIONS}

The most common health complaints of rubber plantation workers reported in the present study were musculoskeletal (66.2\%), respiratory $(31.2 \%)$, dermatological $(26.6 \%)$ and ophthalmological disorders $(22.7 \%)$. Hence, there is a need for proper health and safety training of rubber plantation workers on workplace hazards and ergonomics to reduce work-related morbidities. Use of correct and adequate personal protective devices at the rubber plantations needs to be stressed among these workers. Further research is required to quantify the effects of chemical exposure on the health of rubber plantation workers.

Efforts should be made to enhance access to healthcare for vulnerable sections of society like unorganized sector workers. Periodic health checkups is a must to improve health among these workers. Awareness of noncommunicable diseases \& the importance of early diagnosis and continuous treatment should also be increased through health education campaigns.

\section{ACKNOWLEDGEMENTS}

The authors would like to thank the rubber plantation workers and the plantation owners for their interest, cooperation and participation in the study.

\section{REFERENCES}

1. George TK, Haridasan V and Sreekumar B. Role of Government and Structural Changes in Rubber Plantation Industry.
JSTOR: Economic and Political Weekly. 1986;23(48):158-66.

2. Chester $\mathrm{G}$ and Woolen $\mathrm{BH}$. Studies of the occupational exposure of Malaysian plantation workers to paraquat. British Journal of Industrial Medicine 1981;38:23-33.

3. Sri-Akajunt N, Sadhra S, Jones M and Burge PS. Natural rubber latex aeroallergen exposure in rubber plantation workers and glove manufacturers in Thailand and health care workers in a UK hospital. Ann Occup Hyg 2000;44(2):79-88.

4. Reddy VD, Kumar BS and Uzma N. Lung Function Parameters, Neck Pain And Associated Factors Among Male Rubber Tapping Workers In Kerala. Int J Pharm Med \& Bio Sc 2012;1(2):43-8.

5. Looareesuwan $\mathrm{S}$, Viravan $\mathrm{C}$ and Warrell DA.Factors contributing to fatal snake bite in the rural tropics: analysis of 46 cases in Thailand. Trans R Soc Trop Med Hyg 1988;82(6):930-4.

6. Zahedi M, Oothuman P, Sabapathy NN and Bakar NA. Intestinal nematode infections and efficacy study of oxantel-pyrantel pamoate among plantation workers.

7. Bhumiratana A, Sorosjinda-Nunthawarasilp P, Kaewwaen W, Maneekan $\mathrm{P}$ and Pimnon $\mathrm{S}$. Malaria-associated rubber plantations in Thailand. Travel Med Infect Dis 2013;11(1):3750 .

8. Kwa BH. Environmental change, development and vectorborne disease: Malaysia's experience with filariasis, scrub typhus and dengue. Environ Dev Sustain 2008;10(2):209-17.

9. Kumar NP, Suresh A, Vanamail $P$, Sabesan $S$, Krishnamoorthy KG, Matthew J, et al. Chikungunya virus outbreak in Kerala, India, 2007: a seroprevalence study. Mem Inst Oswaldo Cruz 2011;106(8):912-6.

10. Giles WH, Pacqué M, Greene BM, Taylor HR, Muñoz B, Cutler M, et al. Prevalence of hypertension in rural west Africa. Am J Med Sci. 1994;308(5):271-5.

11. Registrar General of India. Census of India 2011: Data from the 2011 Census, including cities, villages and towns (Provisional).

12. James PA, Oparil S, Carter BL, Cushman WC and Dennison-Himmelfarb C. 2014 Evidence-Based Guideline for the Management of High Blood Pressure in Adults: Report From the Panel Members Appointed to the Eighth Joint National Committee (JNC 8). JAMA 2014;311(5):507-20.

13. World Health Organisation. Definition and diagnosis of diabetes mellitus and intermediate hyperglycemia: Report of a WHO/IDF consultation. 2006.

14. Deshingkar P. Internal Migration, Poverty and Development in Asia: Including the Excluded. IDS Bulletin 2006;37(3):88-100

15. Thankappan KR, Shah B, Mathur P, Sarma PS, Srinivas G, Mini GK, et al. Risk factor profile for chronic non-communicable diseases: results of a community-based study in Kerala, India. Indian J Med Res 2010;131:53-63.

\footnotetext{
Authors Contribution:

TSN - Concept, review of literature, data collection, statistical analysis, manuscript preparation; SG - Concept and study design, critical revision of manuscript;

MMS - Concept, statistical interpretation, critical revision of manuscript.

Source of Support: Nil. Conflict of Interest: None.
} 